BASIC RESEARCH

\title{
Proportion of fibrin and platelets differs in thrombi on ruptured and eroded coronary atherosclerotic plaques in humans
}

\author{
Y Sato, K Hatakeyama, A Yamashita, K Marutsuka, A Sumiyoshi, Y Asada
}

Heart 2005;91:526-530. doi: 10.1136/hrt.2004.034058

See end of article for authors' affiliations .....................

Correspondence to: Dr Yujiro Asada, First Department of Pathology, Miyazaki Medical College, 5200 Kihara, Kiyotake, Miyazaki 889-1692, Japan; yasada@fc. miyazaki-u.ac.jp

Accepted 24 May 2004
Objective: To determine the proportion of platelets and fibrin in coronary thrombi.

Design: Immunohistochemical and morphometric means to examine the coronary arteries of 31 patients who died of acute myocardial infarction.

Results: Fresh thrombi were detected in the feeding arteries of infarction areas in 23 cases $(74 \%)$ and were associated with plaque rupture in $18(78 \%)$ and plaque erosion in $5(22 \%)$. An immunohistochemical study showed that the thrombi consisted of a mixture of fibrin and platelets as well as some other types of blood cells. The fibrin and platelet positive areas in the thrombi associated with plaque rupture accounted for 74 (19)\% and $35(20) \%(p<0.01$ ) and those associated with erosion accounted for $51(6) \%$ and $70(21) \%$, respectively, of the total areas. Areas of positive immunoreactivity for tissue factor and $\mathrm{C}$ reactive protein were also significantly greater in ruptured than in eroded plaques.

Conclusion: These results indicate that the proportions of fibrin and of platelets differ in coronary thrombi on ruptured and eroded plaques. Higher proportions of tissue factor and $\mathrm{C}$ reactive protein contribute more significantly to thrombus formation on plaque rupture than on plaque erosion.
$\mathrm{T}$ hrombus formation on disrupted atherosclerotic plaques plays a fundamental part in the development of acute coronary syndromes and in the progression of atherosclerosis. ${ }^{1}$ Coronary thrombosis occurs most often in lipid rich ruptured plaques, but eroded plaques lacking a superficial lipid core or that do not rupture are also often associated with acute coronary syndromes. ${ }^{2-6}$ The thrombogenicity of atherosclerotic lesions mostly depends on the nature and extent of the plaque components exposed to the circulating blood flow. Since platelet adhesion and aggregation are essential steps in haemostatic and thrombotic processes, the development of platelet rich thrombi has been regarded as a trigger of acute coronary syndromes. ${ }^{78}$ However, the effect of antiplatelet administration is quite variable in terms of reducing the incidence of death, myocardial infarction, or the need for further intervention. ${ }^{9-11}$ In addition, necropsy studies have shown that thrombi causing myocardial infarction contain not only platelets but also a large amount of fibrin, suggesting an increase in activation of the coagulation cascade during the event. ${ }^{12}{ }^{13}$ We and others have shown that tissue factor expressed in atherosclerotic lesions is an important determinant of thrombogenicity that contributes to fibrin-rich thrombus formation after plaque disruption. ${ }^{14-17}$ However, the thrombus components that develop on plaque rupture and during erosion are unknown.

We therefore investigated immunohistochemically the nature of thrombi that developed on plaque rupture and erosion. We also measured the expression of tissue factor and $C$ reactive protein (CRP), a non-specific marker of inflammation and a predictor of incident cardiovascular events, in disrupted coronary plaques from necropsies. ${ }^{18} 19$

\section{METHODS}

\section{Selection of cases}

We examined the hearts of 31 patients who had died of acute myocardial infarction within three days of onset. Necropsies were performed at Miyazaki Medical College Hospital and Miyazaki Prefectural Hospital. Acute myocardial infarction was defined as typical chest symptoms lasting over 30 minutes, ST-T wave changes or abnormal Q waves on ECG, and serum creatine kinase concentrations above twice the upper normal limit. Patients who had undergone coronary intervention were excluded from this study. This study protocol was approved by the ethics committee of Miyazaki Medical College.

\section{Coronary artery evaluation}

All hearts were initially examined while fresh and then fixed whole at the time of necropsy. The coronary arterial trees were gently perfusion fixed with $10 \%$ buffered formalin to prevent any distortion of coronary thrombi and were further immersed in the same fixative for 72 hours at room temperature. The major epicardial coronary arteries (left main, left anterior descending, left circumflex, and right coronary arteries) and their major branches (left diagonal and left obtuse marginal branches and posterior descending coronary artery) were cut transversely at $3 \mathrm{~mm}$ intervals (following decalcification if necessary). Segments with over $50 \%$ cross sectional luminal stenosis according to a visual inspection were histologically analysed. ${ }^{3}$ These segments were embedded in paraffin, cut into $4 \mu \mathrm{m}$ thick sections, and then visualised by haematoxylin and eosin, Mallory azan, and elastica van Gieson staining.

Samples with coronary thrombi were separated based on the morphology of the underlying plaque as follows ${ }^{3}$ : plaque rupture with a disrupted fibrous cap over a lipid core with an acute thrombus continuous to the lipid pool (fig 1A); and those with superficial erosion (without plaque rupture) in which an acute thrombus directly contacted the intimal plaque without a ruptured lipid pool (fig 2A). Lipid cores located deep within the unruptured plaques with superficial erosion did not communicate with the thrombus. Segments with luminal thrombi without rupture into the lipid core were serially step sectioned and stained (at every $20 \mu \mathrm{m}$ for at least 1 to $2 \mathrm{~cm}$ ) to determine whether the fibrous cap was ruptured. 


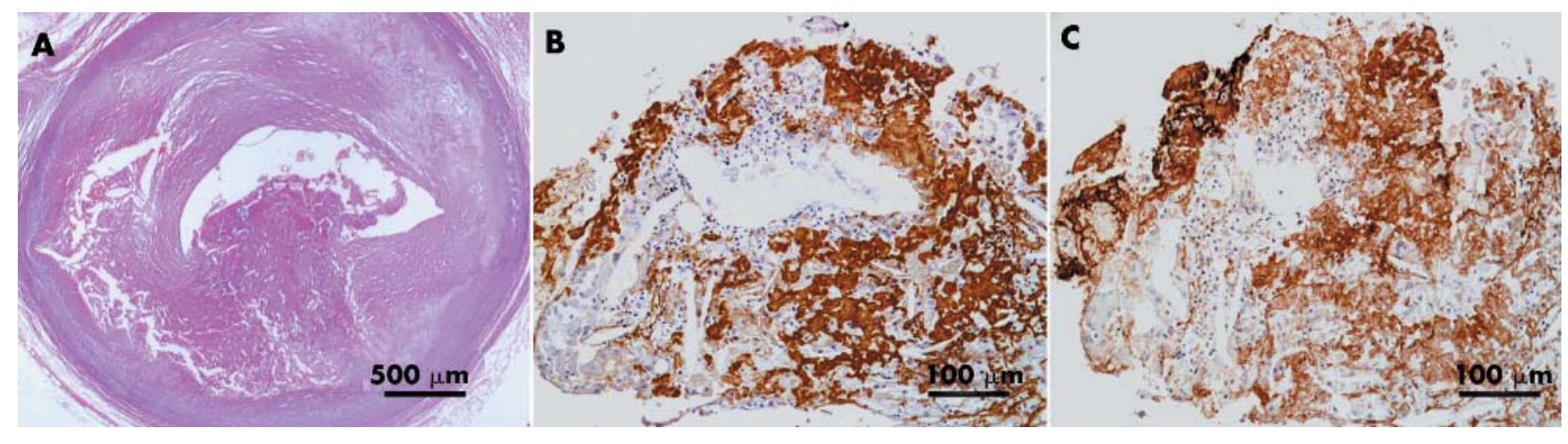

Figure 1 Representative micrographs of plaque rupture with thrombus. (A) Thrombus on ruptured plaque (haematoxylin and eosin stain). Extensive necrotic core contains foamy macrophages and disrupted fibrous cap. Thrombus is composed of large amount of (B) fibrin and (C) platelets.

Coronary artery segments that contained acute thrombi determined by light microscopy (luminal collections of platelet, fibrin, or both, with or without trapped erythrocytes and white blood cells) were selected for immunohistochemical and morphometric evaluation. Deparaffinised sections were immunohistochemically stained with avidin-biotin complex and antibodies to fibrin (Takeda Chemical Industries, Ltd, Osaka, Japan), ${ }^{20}$ platelet glycoprotein IIb (CD41, DAKO Japan, Kyoto, Japan), tissue factor (ChemoSero-Therapeutic Research Institute, Kumamoto, Japan), CRP (DAKO Japan), macrophages (DAKO Japan), and smooth muscle cells ( $\alpha$ smooth muscle actin, DAKO Japan). Sections were counterstained with haematoxylin. Positive and negative controls were included in parallel for every stain. The extent of immunoreactive areas of fibrin or platelet was quantified in at least 10 serial step sections from each necropsy sample with an image analysis system (SPICA-11, Nippon Avionics Co, Tokyo, Japan) and was expressed as the percentage of the total amount of thrombus area. We also evaluated areas positive for tissue factor or CRP in underlying plaques at rupture or erosion sites (in areas of $1 \mathrm{~mm}^{2}$ ).

\section{Risk factors}

The following risk factors for coronary artery disease were assessed from medical records and compared between cases of plaque rupture and of erosion: age, sex, hypertension, diabetes mellitus, hypercholesterolaemia, and smoking habit. The presence or absence of risk factors was determined as follows. Hypertension was considered to be present when long term treatment had been given or was required. Diabetes mellitus was defined by a previous physician's diagnosis and treatment with insulin, oral hypoglycaemic agents, or diet. Hypercholesterolaemia was defined as a serum total cholesterol concentration of over $5.7 \mathrm{mmol} / \mathrm{l}$. Current smokers were considered to have had a smoking habit.

\section{Statistical analysis}

Data are presented as mean (SD). Continuous variables were compared by analysis of variance and categorical variables were compared by the $\chi^{2}$ test (StatView software, version 5.0; SAS Institute, Cary, North Carolina, USA). A probability value of $\mathrm{p}<0.05$ was considered significant.

\section{RESULTS}

The mean (SD) age of the 24 men and seven women at the time of death was 68 (10) years (range 49-95 years). Twenty three of $31(74 \%)$ had acute thrombi in the major epicardial coronary arteries (left anterior descending, seven; left circumflex, six; and right coronary artery, 10). Of the 23 acute thrombosed coronary artery plaques, 18 were plaque ruptures $(78 \%, 16$ men and two women) and five were

Table 1 Proportion of immunoreactive areas in thrombi and disrupted plaques

\begin{tabular}{|c|c|c|c|}
\hline & $\begin{array}{l}\text { Ruptured } \\
\text { plaques }\end{array}$ & $\begin{array}{l}\text { Eroded } \\
\text { plaques }\end{array}$ & $\mathrm{p}$ Value \\
\hline \multicolumn{4}{|l|}{ Thrombus } \\
\hline Fibrin (\%) & $74(19)$ & $51(6)$ & 0.03 \\
\hline Platelets (\%) & $35(20)^{*}$ & $70(21) \dagger$ & 0.01 \\
\hline \multicolumn{4}{|l|}{ Plaque } \\
\hline Tissue factor (\%) & $22(6)$ & $2(1)$ & 0.002 \\
\hline $\mathrm{C}$ reactive protein $(\%)$ & $15(5)$ & 2 (1) & 0.007 \\
\hline
\end{tabular}

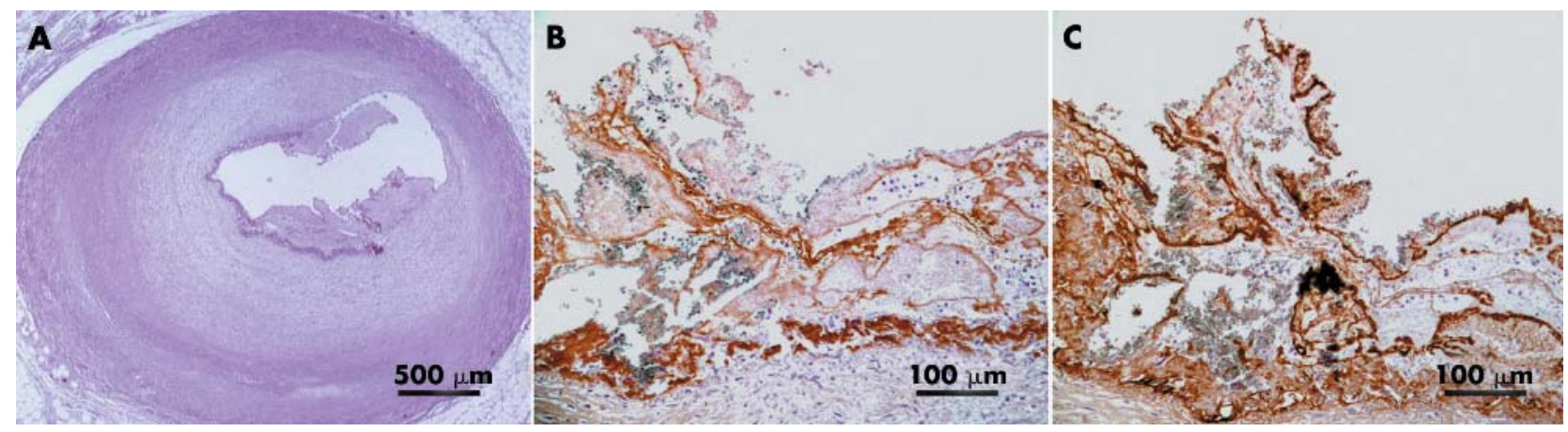

Figure 2 Representative micrographs of plaque erosion with thrombus. (A) Non-occlusive thrombus on eroded plaque (haematoxylin and eosin stain). Plaque is fibrous and without visible atheromatous component. Thrombus is composed of (B) fibrin and (C) platelet mixtures and is relatively more rich in platelets than in fibrin. 

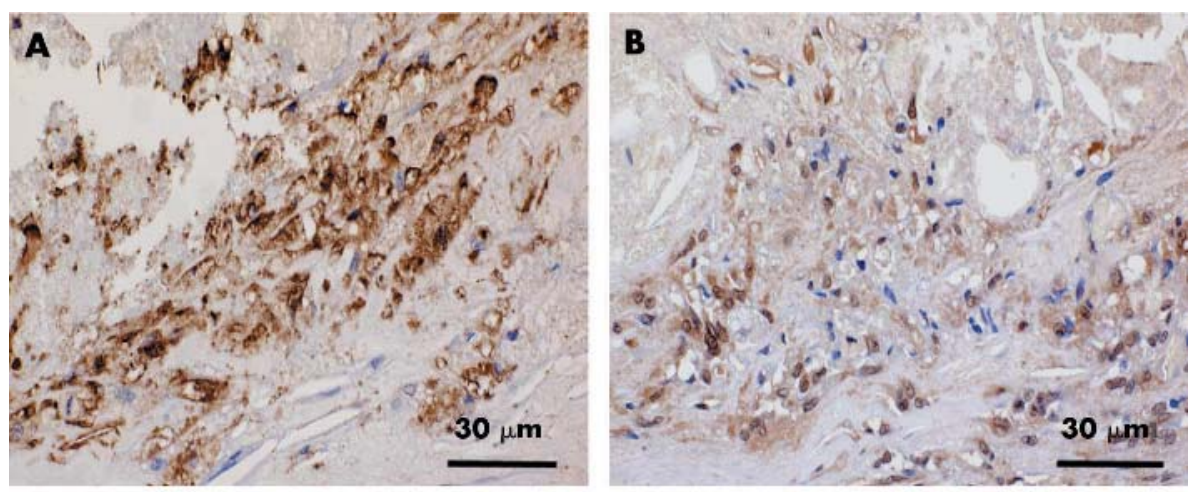

Figure 3 Representative immunohistochemical micrographs of $(A, B)$ ruptured and $(C, D)$ eroded plaques. Ruptured plaque is intensely immunoreactive for (A) tissue factor and (B) $C$ reactive protein. Eroded fibrous plaque is weakly stained for (C) tissue factor and (D) C reactive protein.
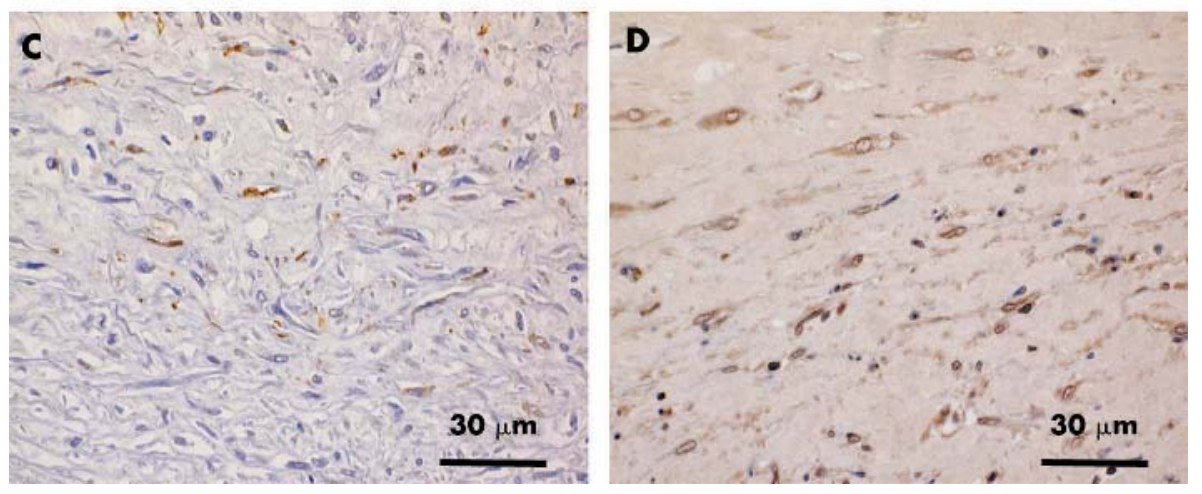

superficial erosions (22\%, four men and one woman) (figs $1 \mathrm{~A}$ and $2 \mathrm{~A}$ ).

\section{Thrombi on plaque rupture or erosion}

The immunohistochemical study showed that all thrombi that developed on plaque rupture and erosion were composed of a mixture of fibrin and platelets. Fibrin was more abundant than platelets in thrombi on ruptured plaque (fig 1B, C). Image analysis showed an immunopositive area for fibrin that was significantly greater than that for platelets (table 1). In contrast, the thrombi on eroded plaques were relatively but not significantly richer in platelets than in fibrin (fig 2B, $\mathrm{C}$, table 1). Foci of macrophages at the luminal surface adjacent to the thrombus were present in all 18 ruptured plaques $(100 \%)$ versus three eroded plaques $(60 \%)$. In contrast, smooth muscle cells were clustered at the luminal surface adjacent to the thrombus in all eroded plaques $(100 \%)$ compared with four ruptured plaques $(22 \%)$.

\section{Tissue factor and CRP in plaques}

Underlying rupture was intensely immunoreactive for both tissue factor and CRP. Many foamy macrophages, smooth muscle cells, and extracellular matrix in the plaques were intensely positive for tissue factor and CRP (fig 3A, B). In contrast, smooth muscle cells and extracellular matrix in the

Table 2 Risk factors and types of disrupted plaques

\begin{tabular}{llll}
\hline & $\begin{array}{l}\text { Ruptured } \\
\text { plaques }\end{array}$ & $\begin{array}{l}\text { Eroded } \\
\text { plaques }\end{array}$ & $\mathrm{p}$ Value \\
\hline Age (years) & $70(8)$ & $68(10)$ & $>0.4$ \\
Men:women & $16: 2$ & $4: 1$ & 0.25 \\
Hypercholesterolaemia & $1(5 \%)$ & $1(20 \%)$ & 0.14 \\
Diabetes mellitus & $3(16 \%)$ & $1(20 \%)$ & 0.31 \\
Hypertension & $4(22 \%)$ & $2(40 \%)$ & 0.22 \\
Cigarette smoking & $1(5 \%)$ & $1(20 \%)$ & 0.14 \\
\hline \multicolumn{2}{l}{ Data are mean (SD) or number (\%). } \\
\end{tabular}

eroded plaques were focally positive for tissue factor and CRP (fig 3C, D). The stained areas for these antigens were significantly greater in the plaques underlying rupture than those underlying erosion (table 1).

\section{Risk factors}

Age, sex, incidence of hypercholesterolaemia, diabetes mellitus, hypertension, and smoking did not differ significantly between plaque rupture and erosion (table 2).

\section{DISCUSSION}

The present study showed that the thrombi of ruptured plaques were more significantly rich in fibrin and that more tissue factor and CRP were expressed in ruptured than in eroded plaques.

Acute coronary thrombosis leading to acute myocardial infarction may arise from a difference in underlying plaque morphology, namely rupture and superficial erosion. ${ }^{2-6}$ In acute coronary death with coronary thrombosis, two necropsy studies have found plaque rupture in $75 \%$ of cases and that erosion accounted for the remainder. ${ }^{26}$ Kojima and colleagues $^{5}$ found plaque rupture in $81 \%$ and erosion in $19 \%$ of Japanese patients who died of acute myocardial infarction. ${ }^{5}$ The findings of the present study agree with these previous results. In contrast, Farb and colleagues ${ }^{3}$ and Burke and associates ${ }^{4}$ have reported that $56 \%$ of such deaths are associated with plaque rupture and $44 \%$ with erosion. In addition, they found plaque erosion in $69 \%$ of women who died of sudden ischaemic heart disease. ${ }^{34}$ These reports emphasised a high rate of plaque erosion, especially among young or premenopausal women. Because of the very limited number of women in the present study, we could not evaluate the influence of sex on plaque morphology. A necropsy study by Kojima and colleagues ${ }^{5}$ found plaque erosion in $31 \%$ of the Japanese women studied, indicating potential race differences in the incidence of this condition.

Clinical and experimental animal studies have provided evidence of the role of plaque disruption and acute thrombus 
formation in the onset of acute coronary events. ${ }^{71}$ The most widely accepted hypothesis is that plaque disruption activates circulating platelets by exposing the subendothelium to blood circulation and that subsequent platelet adhesion and aggregation result in obstructive thrombus formation. ${ }^{78}$ On the basis of this hypothesis, antagonists for the platelet glycoprotein IIb/IIIa receptor, which is a final common pathway of platelet aggregation, have been tested in randomised, placebo controlled trials of acute coronary syndromes and in percutaneous coronary intervention. For patients undergoing percutaneous revascularisation, these agents have reduced the incidence of death, myocardial infarction, and the need for urgent reintervention. ${ }^{90}$ However, trials of glycoprotein IIb/IIIa receptor antagonists for patients with acute coronary syndromes have yielded more modest or less apparent benefits, ${ }^{11}$ which raises the notion of a different mechanism of thrombus formation on plaque disruption. Necropsy studies of acute myocardial infarction have shown that only $15 \%$ of occlusions consist of pure platelet thrombus, whereas $85 \%$ of occlusive thrombi are largely composed of fibrin as well as platelets. ${ }^{13}$ We have also shown that all of the thrombi detected at plaque disruption sites consisted of a mixture of fibrin and platelets and that fibrin was more abundant in thrombi on ruptured plaque. These findings indicate that antiplatelet treatment may have variable effects on acute coronary events and suggest that a combination of antiplatelet and anticoagulant agents would be more favourable. Recent clinical studies have shown that aspirin in combination with anticoagulants is more effective than aspirin alone in reducing the incidence of serious cardiovascular events and death after acute coronary events, although the risk of bleeding is increased..$^{22}$

Tissue factor immunoreactivity was more prominent in ruptured than in eroded plaques. Consistently expressed mainly in macrophages and smooth muscle cells of plaques, tissue factor induces procoagulant activity in atherosclerotic lesions. ${ }^{14}{ }^{1624}$ Evidence suggests that increased activity of the tissue factor mediated coagulation cascade significantly contributes to thrombus formation at plaque disruption sites. The presence of abundant tissue factor in ruptured plaques is considered to contribute to fibrin-rich thrombus formation. Plasma concentrations of tissue factor are significantly increased in patients with ischaemic heart diseases. ${ }^{25}$ Meanwhile, a crucial role of circulating tissue factor in the process of thrombus formation has been proposed ${ }^{26}$ and the present study found positive tissue factor immunoreactivity in thrombi (data not shown), which supports this notion.

In the underlying plaque associated with rupture, CRP immunoreactivity was significantly more abundant than in that associated with erosion. Previous reports have associated CRP with a risk of future ischaemic heart diseases. ${ }^{18}{ }^{19}$ In addition, CRP mRNA and protein are expressed within atheromatous plaques, being primarily localised to macrophages and extracellularly within the lipid core. ${ }^{27}{ }^{28}$ Although we could not examine serum CRP concentrations in our necropsy cases, Burke and colleagues $^{29}$ found a positive correlation between the intensity of CRP staining and serum concentrations of CRP. However, the importance of CRP to plaque rupture and thrombosis remains unclear. A functional significance to these pathological findings has been suggested by co-localisation with components of the complement system within atherosclerotic plaques. ${ }^{30}$ Indeed, CRP can actively stimulate the classic complement pathway and enhance phagocytic activity as an important mediator of innate immunity. ${ }^{31}$ Within atherosclerotic plaques, CRP mediated opsonisation may be important for low density lipoprotein uptake by macrophages and foam cell formation. ${ }^{32}$ In vitro studies have shown that CRP enhanced the expression of adhesion molecules in endothelial cells and induced high concentrations of tissue factor expression in monocytes. ${ }^{33}{ }^{34}$ These lines of evidence suggest that abundant CRP deposition within plaques contributes not only to the regulation of the inflammatory process but also to thrombus propagation.

\section{Study limitations}

Because the present study examined a small number of cases, especially of women, we could not evaluate the inherent bias in the selection of patients for necropsy. It is difficult to draw firm conclusions regarding the differences between the findings on rupture and on erosion, since the eroded plaques were found in only five patients as opposed to 18 with ruptured plaques. In addition, the information source for risk factors was limited to a single postmortem collection and the duration of risk factor exposure was not available. Information regarding risk factor modification (for example, aspirin, hormone replacement therapy, and statin use) was often incomplete.

\section{ACKNOWLEDGEMENTS}

We thank Drs Tohru Hayashi (Miyazaki Prefectural Miyazaki Hospital) and Akira Ishihara (Miyazaki Prefectural Nobeoka Hospital) for providing permission to review their necropsy cases. This study was supported by Grants-in-Aid for Scientific Research (No 14570153) and for the 21st Century COE program (Life Science) from The Ministry of Education, Science, Sports, and Culture, Japan, and by a grant from the Terumo Foundation, Japan.

\section{Authors' affiliations}

Y Sato, K Hatakeyama, A Yamashita, K Marutsuka, A Sumiyoshi, Y Asada, First Department of Pathology, Miyazaki Medical College, Miyazaki, Japan

\section{REFERENCES}

1 Fuster V, Badimon JJ, Chesebro JH. The pathogenesis of coronary artery disease and the acute coronary syndromes. N Engl J Med 1992;326:242-50.

2 Davies MJ, Thomas AC. Plaque fissuring: the cause of acute myocardial infarction, sudden ischaemic death, and crescendo angina. Br Heart $J$ 1985;53:363-73

3 Farb A, Burke AP, Tang AL, et al. Coronary plaque erosion without rupture into a lipid core: a frequent cause of coronary thrombosis in sudden coronary death. Circulation 1996;93:1354-63.

4 Burke AP, Farb A, Malcom GT, et al. Coronary risk factors and plaque morphology in men with coronary disease who died suddenly. N Engl J Med 1997:336:1276-82

5 Kojima S, Nonogi $\mathrm{H}$, Miyao $\mathrm{Y}$, et al. Is preinfarction angina related to the presence or absence of coronary plaque rupture? Heart 2000;83:64-8.

6 Arbustini E, Dal Bello B, Morbini P, et al. Plaque erosion is a major substrate for coronary thrombosis in acute myocardial infarction. Heart 1999:82:269-72

7 Fuster V. Acute coronary syndromes: the degree and morphology of coronary stenoses. J Am Coll Cardiol 2000;35:52B-4B.

8 Willerson JT, Golino P, Eidt J, et al. Specific platelet mediators and unstable coronary artery lesions: experimental evidence and potential clinical implications. Circulation 1989;80:198-205.

9 Vorchheimer DA, Badimon JJ, Fuster V. Platelet glycoprotein Ilb/Illa receptor antagonists in cardiovascular disease. JAMA 1999;281:1407-14.

10 Coller BS. Anti-GPIlb/Illa drugs: current strategies and future directions. Thromb Haemost 2001;86:427-43.

11 Simoons ML. Effect of glycoprotein Ilb/Illa receptor blocker abciximab on outcome in patients with acute coronary syndromes without early coronary revascularisation: the GUSTO IV-ACS randomised trial. GUSTO IV-ACS Investigators. Lancet 2001;357:1915-24.

12 Davies MJ. Stability and instability: two faces of coronary atherosclerosis. Circulation 1996;94:2013-20.

13 Rentrop KP. Thrombi in acute coronary syndromes: revisited and revised. Circulation 2000;101:1619-26.

14 Wilcox JN, Smith KM, Schwartz SM, et al. Localization of tissue factor in the normal vessel wall and in the atherosclerotic plaque. Proc Natl Acad Sci USA 1989;86:2839-43

15 Taubman MB, Fallon JT, Schecter AD, et al. Tissue factor in the pathogenesis of atherosclerosis. Thromb Haemost 1997;78:200-4.

16 Hatakeyama K, Asada Y, Marutsuka K, et al. Localization and activity of tissue factor in human aortic atherosclerotic lesions. Atherosclerosis 1997; 133:213-9

17 Hatakeyama K, Asada Y, Marutsuka K, et al. Expression of tissue factor in the rabbit aorta after balloon injury. Atherosclerosis 1998;139:265-71. 
18 Ridker PM, Hennekens $\mathrm{CH}$, Buring JE, et al. C-reactive protein and other markers of inflammation in the prediction of cardiovascular disease in women. N Engl J Med 2000;342:836-43

19 Kuller LH, Tracy RP. The role of inflammation in cardiovascular disease. Arterioscler Thromb Vasc Biol 2000;20:901.

20 Kurokawa T, Iwasa S, Kakinuma A, et al. Enhancement of clot lysis in vitro and in vivo with a bispecific monoclonal antibody directed against human fibrin and against urokinase- type plasminogen activator. Thromb Haemost $1991 ; 66: 684-93$

21 Gutstein DE, Fuster V. Pathophysiology and clinical significance of atherosclerotic plaque rupture. Cardiovasc Res 1999;41:323-33.

22 Hurlen $M$, Abdelnoor $M$, Smith $P$, et al. Warfarin, aspirin, or both after myocardial infarction. N Engl J Med 2002;347:969-974.

23 Van Es RF, Jonker JJ, Verheugt FW, et al. Aspirin and coumadin after acute coronary syndromes (the ASPECT-2 study): a randomised controlled trial. Lancet 2002;360:109-13.

24 Moons AH, Levi M, Peters RJ. Tissue factor and coronary artery disease. Cardiovasc Res 2002;53:313-25.

25 Misumi K, Ogawa H, Yasue H, et al. Comparison of plasma tissue factor level in unstable and stable angina pectoris. Am J Cardiol 1998;81:22-6.

26 Giesen PL, Rauch U, Bohrmann B, et al. Blood-borne tissue factor: another view of thrombosis. Proc Natl Acad Sci USA 1999;96:2311-5.
27 Torzewski M, Rist C, Mortensen RF, et al. C-reactive protein in the arterial intima: role of $C$-reactive protein receptor-dependent monocyte recruitment in atherogenesis. Arterioscler Thromb Vasc Biol 2000;20:2094-9.

28 Yasoijima K, Schwab C, McGeer EG, et al. Generation of C-reactive protein and complement components in atherosclerotic plaques. Am J Pathol 2001;158:1039-51.

29 Burke AP, Tracy RP, Kolodgie F, et al. Elevated C-reactive protein values and atherosclerosis in sudden coronary death: association with different pathologies. Circulation 2002;105:2019-23.

30 Bhakdi S, Torzewski $M$, Klouche $M$, et al. Complement and atherogenesis: binding of CRP to degraded, nonoxidized LDL enhances complement activation. Arterioscler Thromb Vasc Biol 1999;19:2348-54.

31 Mold C, Gewurz H, Du Clos TW. Regulation of complement activation by C-reactive protein. Immunopharmacology 1999:42:23-30.

32 Zwaka TP, Hombach V, Torzewski J. C-reactive protein-mediated low density lipoprotein uptake by macrophages: implications for atherosclerosis. Circulation 2001;103:1194-7.

33 Pasceri V, Willerson JT, Yeh ET. Direct proinflammatory effect of C-reactive protein on human endothelial cells. Circulation 2000;102:2165-8.

34 Cermak J, Key NS, Bach RR, et al. C-reactive protein induces human peripheral blood monocytes to synthesize tissue factor. Blood 1993;82:513-20.

\section{IMAGES IN CARDIOLOGY}

\section{Complete aspiration of thrombi from an occluded coronary artery}

A

43 year-old male heavy smoker with no specific medical history was brought to our hospital with sudden chest pain. An ECG revealed ST segment elevation in precordial leads. An echocardiogram detected severe hypokinesis in the anterior wall of the left ventricle. After intravenous administration of heparin ( $10000 \mathrm{IU}$ ), the patient underwent coronary angiography, which demonstrated total occlusion of the dilated left anterior descending coronary artery (panel A, video A) (to view video A visit the Heart website-http:// www.heartjnl.com/supplemental). A 0.014 inch guidewire easily crossed the occlusion. Thrombectomy was attempted with the Thrombuster aspiration catheter (Kaneka Medical, Tokyo, Japan). Intraluminal coronary artery blood around the occlusion site was collected through several aspirations. A number of red cylindrical thrombi were caught by the filter (panel B). Histological examination of the aspirates revealed that the thrombi were exclusively composed of fibrin and red blood cells with a few haematopoietic cells (panel D, bar $5 \mathrm{~mm}$ ). No atheromatous plaque was detected. After the thrombectomy, angiography revealed no haziness of the left anterior descending coronary artery and good blood flow (TIMI grade 3; panel $\mathrm{C}$, video $\mathrm{B}$ ) (to view video $\mathrm{B}$ visit the Heart website-http://www.heartjnl. com/supplemental). The patient recovered well on aspirin, ticlopidine, and carvedilol. The follow up angiography showed no organic lesion in the coronary arteries.
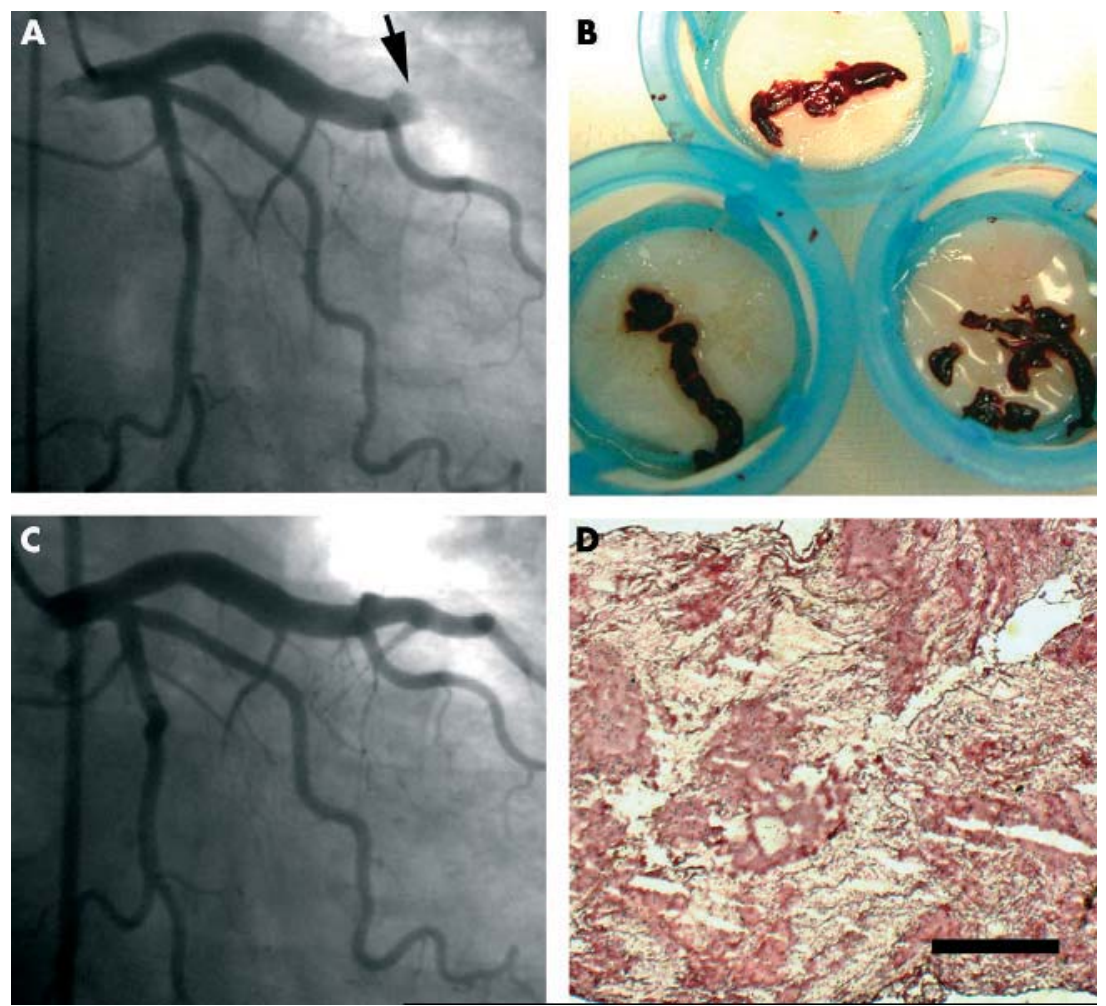

To view video clips visit the Heart websitehttp://www.heartinl.com/supplemental 